\title{
Quantifying the effect of early retirement on the wealth of individuals with depression or other mental illness
}

Deborah J. Schofield, Rupendra N. Shrestha, Richard Percival, Simon J. Kelly, Megan E. Passey and Emily J. Callander

\section{Background}

In addition to the health burden caused by menta illnesses, these conditions contribute to economic disadvantage because of their impact on labour force participation.

\section{Aims}

To quantify the cost of lost savings and wealth to Australians aged 45-64 who retire from the labour force early because of depression or other mental illness.

\section{Method}

Cross-sectional analysis of the base population of Health\&WealthMOD, a microsimulation model built on data from the Australian Bureau of Statistics' Survey of Disability, Ageing and Carers and STINMOD, an income and savings microsimulation model.

\section{Results}

People who are not part of the labour force because of depression or other mental illness have $78 \%(95 \% \mathrm{Cl} 92.2$ $37.1)$ and $93 \%(95 \% \mathrm{Cl} 98.4-70.5)$ less wealth accumulated respectively, compared with people of the same age, gender and education who are in the labour force with no chronic health condition. People who are out of the labour force as a result of depression or other mental illness are also more likely to have the wealth that they do have in cash assets, rather than higher-growth assets such as superannuation, home equity and other financial investments.

\section{Conclusions}

This lower accumulated wealth is likely to result in lower living standards for these individuals in the future. This will compound the impact of their condition on their health and quality of life, and put a large financial burden on the state as a result of the need to provide financial assistance for these individuals.

\section{Declaration of interest}

None.
The large direct medical costs of mental illness are generally attributed to the condition's high prevalence rates. ${ }^{1,2}$ Mental illness prevalence rates of one in four people are not uncommon in many countries. ${ }^{2,3}$ For individuals with depression and other mental illness, in addition to the impact on health and quality of life these conditions contribute to economic disadvantage because of the impact on labour force participation.

The labour force participation rate for people with a mental illness is acknowledged to generally be poor. ${ }^{4}$ A recent study estimated that $51 \%$ of Australians aged 45-64 with a mental illness and $53 \%$ of those with depression are not part of the workforce, significantly more than the 17\% of 45-64 year olds with no chronic health conditions who are not part of the labour force. ${ }^{5}$ The impact of this low rate of labour force participation is reflected in the incomes of those with a mental illness; they have $37 \%$ lower average weekly incomes than people without a chronic illness (details available from the author on request). This reduction in labour force participation and income can have a lifetime impact.

Early retirement may leave a large number of mentally ill people with reduced savings or accumulated wealth to finance their retirement years. The impact of the loss of savings is particularly significant for those aged $45-64$, as this is the age bracket where most lifetime savings and wealth accumulation occurs. ${ }^{6}$ This wealth is generally required to finance retirement, and as life expectancy increases, this wealth will have to support longer periods in retirement. ${ }^{7-9}$

Although there have been studies that link mental illness with reduced incomes, ${ }^{1,2,10}$ there is little published research assessing the impact of early retirement owing to mental illness on wealth or savings. Indeed, there has been little research on the link between early retirement due to any illness and lost savings and wealth, with just a handful of studies examining the relationship between general health status and wealth. ${ }^{11,12}$ This study uses the recently developed Health\&WealthMOD - an up-to-date microsimulation model of health, employment, income, and wealth - to quantify the cost of lost savings and wealth on people aged 45-64 who retire from the labour force early because of mental illness.

\section{Method}

\section{Data}

For this study the output data-set of a microsimulation model, Health\&WealthMOD, was analysed. Health\&WealthMOD was specifically designed to measure the economic impact of ill health on Australian workers aged 45 to 64 years. It is Australia's first microsimulation model of health and its associated impact on labour force participation, personal income and wealth and government revenue. Health\&WealthMOD was built on the unit record data of the 2003 Survey of Disability, Ageing and Carers conducted by the Australian Bureau of Statistics ${ }^{13}$ and the output data of a microsimulation model of income and wealth, STINMOD, developed by the National Centre for Social and Economic Modelling for the Australian Government. ${ }^{14}$

The Survey of Disability, Ageing and Carers provides detailed self-reported data on sociodemographic status, labour force participation and health and disability status (such as chronic conditions) for each individual in Health\&WealthMOD. 
Respondents' health conditions were classified by the Australian Bureau of Statistics using ICD-10 ${ }^{15}$ codes. People who reported their main long-term health condition as depression/mood/ affective disorders (excluding postnatal depression) (ICD code F30-39) were considered to have 'depression'. Those who reported their main long-term health condition as mental and behavioural disorders, dementia, schizophrenia, phobic and anxiety disorders, nervous tension/stress, attention-deficit disorder/hyperactivity, and other mental and behavioural disorders (ICD codes F00-29, F40-99) were categorised as 'other mental illness' for this study. Depression was analysed separately from other mental illnesses owing to its high prevalence in the population.

In this study those who reported themselves as being out of the labour force because of their illness and listed depression as their main condition were considered to be out of the labour force because of depression. Those who reported being out of the labour force because of their illness and listed one of the other mental illness conditions as their main condition were deemed to be out of the labour force as a result of other mental illnesses. All people who are out of the labour force, regardless of the reason for it, are assumed to be permanently retired.

Economic information such as income and wealth were imputed from STINMOD. The imputation was carried out by synthetically matching person records with similar sociodemographic and labour force participation characteristics in the two data-sets. Synthetic matching was based on nine matching variables that were common to both data-sets and strongly related to income: gender, income unit type, type of government pension/ support, income quintile, age group, labour force status, hours worked per week, highest educational qualification and home ownership. The data were reweighted to represent the 2009 population and up-rated to reflect the demographic, labour force, income and wealth, and other changes that had occurred between 2003 and 2009. The development of Health\&WealthMOD is explained in detail elsewhere (details available from the author on request).

\section{Statistical methods}

Logistic regression models were used to compare the odds of owning wealth by those who reported being out of the labour force owing to depression and other mental illness (that is, people who were out of the labour force owing to ill health, and identified depression or mental illness as their main health condition) with those who were in full-time work and had no chronic condition. Multiple linear regression models of the log of the value of wealth were used to analyse the differences between the wealth of people working full time with no chronic condition, people working part time with no chronic condition and people not in the labour force because of depression and other mental illness. Full-time work with no chronic condition was used as the reference group. Four different classes of wealth were included - cash, superannuation, value of owner-occupied home and value of other financial investments - as well as the total value of an individual's wealth, which was calculated as the sum of all the above four classes of wealth, and analysed in this paper.

Analyses were separately conducted for all four different classes of wealth and total wealth in both the logistic regression and multiple regression models, adjusted for age group, gender and highest education. Multiple regression analyses were undertaken on log-transformed data in order to satisfy the assumptions of linear regression analysis, and regression diagnostics confirmed that the assumptions were reasonably satisfied. A conservative measure of the impact of retirement as a result of depression or other mental illness on the wealth of individuals was used: only including individuals with depression or another mental illness and who stated that their reason for being out of the labour force was their ill health. A sensitivity analysis was undertaken by including all individuals who had depression or other mental illness and were not in the labour force - regardless of their stated reason for not being in the labour force. The results for assessing the value of total wealth were repeated using this measure.

In order to estimate the results for the entire Australian population in the 45-64 years age group, we performed weighted analysis using weights that represented the number of similar individuals in the Australian population. All analyses were undertaken using SAS V9.2 for Windows. All statistical tests were two sided with the significance level set at 5\%. All results are presented with their $95 \%$ confidence intervals.

\section{Results}

Of the 8864 people living in private accommodation and aged between 45 and 64 years surveyed in the Survey of Disability, Ageing and Carers, there were 43 individuals who were not in the labour force because of depression, and 56 individuals who were not in the labour force because of other mental illnesses. Once weighted, there are 25236 individuals within the Australian population aged 45 to 64 years who were out of the labour force as a result of depression and 39159 individuals who were out of the labour force owing to other mental illness (Table 1). Those who were not in the labour force owing to depression and other mental illness were only 0.09 times (95\% CI $0.02-0.41)$ and 0.03 times (95\% CI $0.01-0.10)$ as likely to have accumulated any type of wealth than those who were employed full time and had no ill health.

Among those who had accumulated any wealth, the median value of this wealth for those who were out of the labour force owing to mental illness other than depression was AU\$112315 (£61 773), which is around half of that for those who are in the labour force either part time or full time with no condition (Table 2). (In 2009, AU\$1 = approximately $\mathfrak{£} 0.55$. In 2009, the purchasing power parity was 1.46 for Australia and 0.619 for the UK with the USA being 1 . The purchasing power parity represents the number of monetary units needed to buy the same representative basket of consumer goods and services. ${ }^{16}$ ) The median value of accumulated wealth for those not in the labour force as a result of depression was AU\$212 809 ( $(2117045$ ), which is larger than the median value of wealth for those out of the labour force because of other mental illness, and only slightly less that the value of total wealth of those in the labour force full time (\$255 199, equivalent to $\mathfrak{£} 140359)$ and part time (\$225652, equivalent to $£ 124109$ ) (Table 2).

Individuals not in the labour force owing to depression or other mental illness who had accumulated some wealth were more likely to have this in cash and were less likely to have other forms of wealth assets (superannuation, home equity and other financial assets) than those in full-time employment but without a chronic condition (Table 3). In particular, they were far less likely to have wealth in superannuation: 0.03 times as likely (95\% CI 0.02-0.08), or $97 \%$ less likely to have accumulated wealth in this asset class for those with depression and 0.02 times as likely (95\% CI $0.01-0.05$ ) or $98 \%$ less likely for those with other mental illnesses, compared with those in full-time employment without a chronic condition.

Figure 1 shows that within the population, there were 70360 people who had depression or another form of mental illness who were not in the labour force but stated that the reason for this was factors other than their ill health. The results of a sensitivity analysis including these people are shown in Table 4 . When all people with depression or other mental illness who are not in the labour force regardless of their reason for this are included 
Table 1 Age and gender distribution of those out of the labour force because of depression and other mental illnesses in the Australian population aged $45-64,2009$

\begin{tabular}{|c|c|c|c|c|c|}
\hline \multirow[b]{2}{*}{ Gender } & \multicolumn{4}{|c|}{ Age, years } & \multirow[b]{2}{*}{ Total } \\
\hline & $45-49$ & $50-54$ & $55-59$ & $60-64$ & \\
\hline \multicolumn{6}{|c|}{ Not in the labour force owing to depression } \\
\hline Male & 3556 & 2854 & 3700 & 2420 & 12530 \\
\hline Female & 5049 & 2572 & 1461 & 3624 & 12706 \\
\hline \multicolumn{6}{|c|}{ Not in the labour force owing to other mental illness } \\
\hline Male & 8189 & 7405 & 6511 & 3684 & 25789 \\
\hline Female & 4884 & 3627 & 2910 & 1949 & 13370 \\
\hline
\end{tabular}

\begin{tabular}{|c|c|c|c|c|c|c|c|c|}
\hline \multirow[b]{2}{*}{ Total wealth } & \multicolumn{5}{|c|}{ Those with any wealth } & \multicolumn{3}{|c|}{ Value of wealthe } \\
\hline & $\begin{array}{l}\text { Population with } \\
\text { any wealth }\end{array}$ & $n^{\mathrm{b}}$ & $\%^{\mathrm{c}}$ & $\begin{array}{l}\text { OR }(95 \% \mathrm{Cl}) \text { of } \\
\text { having wealth }^{\text {d }}\end{array}$ & $P$ & $\begin{array}{l}\text { Mean value of } \\
\text { wealth, AU\$ (f) }\end{array}$ & s.d. & $\begin{array}{l}\text { Median value of } \\
\text { wealth, AU\$ ( } f \text { ) }\end{array}$ \\
\hline Employed full time, no condition & 1403163 & 2256 & 99.7 & 1 & & 398098 (218954) & 490038 & 255199 (140359) \\
\hline Employed part time, no condition & 417098 & 774 & 99.8 & $1.92(0.42-8.75)$ & 0.4018 & 360071 (198 039) & 405432 & 225652 (124 109) \\
\hline Not in labour force owing to depression & 24390 & 40 & 96.7 & $0.09(0.02-0.41)$ & $<0.05$ & $236727(133200)$ & 321339 & $212809(117045)$ \\
\hline $\begin{array}{l}\text { Not in labour force owing to other } \\
\text { mental illness }\end{array}$ & 35329 & 51 & 90.2 & $0.03(0.01-0.10)$ & $<0.0001$ & 148771 (81 824) & 176799 & $112315(61773)$ \\
\hline
\end{tabular}

in the analysis, the median amount of wealth for those with other mental illness is AU\$112315 (£61773), and for those with depression the median value is AU\$212 695 ( $£ 116982$ ). The odds, or chance, of having any wealth for those out of the labour force and reporting other mental illness is 0.03 (95\% CI 0.01-0.08) and for those out of the labour force with depression the odds are 0.03 (95\% CI 0.01-0.12), times the likelihood of having wealth for those in the labour force full time with no chronic condition.

These results are very similar to those in Table 2 for those who have depression or other mental illness who are out of the labour force and state that the reason for this is their ill health. This indicates that the more conservative measure of the impact of retirement because of depression and other mental illness on the wealth of individuals, given in Table 2, is likely to be accurate. Regardless of the measure used there is still a significant difference between the likelihood of having any accumulated wealth for those out of the labour force with mental ill health and for those in the labour force with no ill health.

Of those who reported having any savings, the multiple regression model shows that, compared with those employed full time with no condition, individuals who are not in the labour force owing to depression and other mental illness have on average significantly less wealth overall after adjusting for age, gender and education (Table 4). On average, those who are not in the labour force because of depression have 78\% (95\% CI 92.17-37.09) less wealth than those who are employed full time with no condition (Table 5). Those who are out of the labour force because of other mental illness have 93\% (95\% CI 98.44-70.45) less wealth than those in the labour force full time.

\section{Discussion}

\section{Main finding}

This study has quantified the amount of wealth held by people who have retired from the labour force as a result of depression or other mental illness and also the difference in this amount compared with those who are in the labour force with no chronic ill health. Those out of the labour force because of depression or other mental illness have significantly less wealth. These individuals are also more likely to have the wealth that they do have in cash assets, rather than higher-growth assets such as superannuation, home equity and other financial investments.

The comparatively few individuals out of the labour force because of depression and other mental illness who have any wealth in superannuation is a reflection of the impact of the lower labour force participation rates for these individuals. The impact of depression and other mental illness on labour force participation is significant - those with depression are 6.71 times more likely to be out of the labour force, and those with other mental illness are 5.71 times more likely to be out of the labour force than those with no health condition. ${ }^{5}$ (Although depressive episodes do fluctuate, it has been found that $44 \%$ of people with depression have reoccurring episodes, and individuals with depression spend as much as $19 \%$ of their time in a depressive state $^{17}$ - which indicates why depression, although a fluctuating condition, does cause labour force disruption.) Being absent from the labour force because of depression results in $43 \%$ lower income than being in the labour force full time; and being absent from the labour force owing to other mental disorders results in an income 37\% lower (details available from the author on request). Thus those out of the labour force owing to depression and other mental health conditions do not have the same income with which to accumulate wealth assets; they may even be drawing upon these assets to supplement lost income. However, because of data limitations it is not clear how long the individuals in this study have been out of the labour force.

\section{The full cost of mental illness}

The findings add further support to the arguments that highlight the full extent of the cost of depression and other mental illness. It 


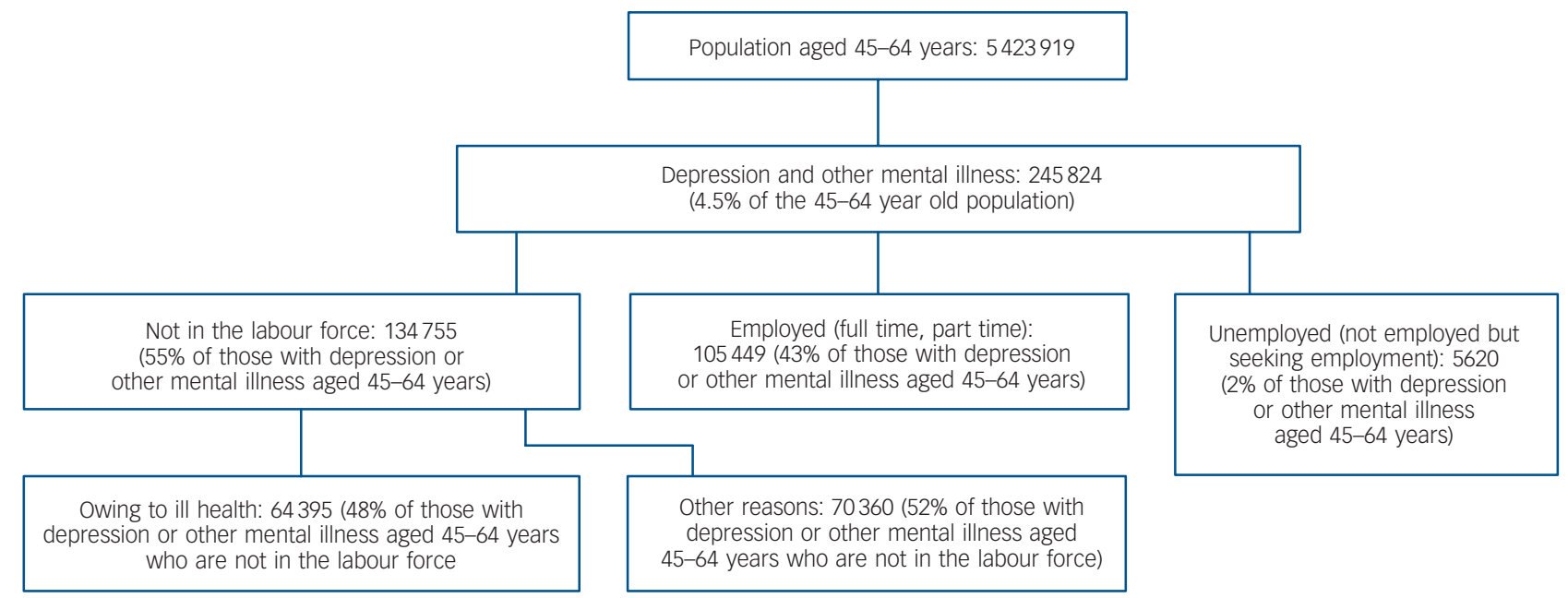

Fig. 1 Flow chart of labour force status for those with depression and other mental illness within the Australian population aged 46-64 years.

has been noted that mental illness alone is responsible for $13.3 \%$ of the burden of disease in Australia, only falling behind cancer and cardiovascular disease. ${ }^{18}$ This highlights the cost of the disease to the health of the Australian population. However, the economic costs are also significant. The cost of treating mental health conditions was estimated to be AU\$3741 million ( $£ 2058$ million) in 2000-01. This estimate covered health expenditure in hospitals, aged care homes, non-hospital medical services, pharmaceuticals, research and community and public health. ${ }^{19}$ However, it should be noted that only $62 \%$ of those with a mental illness seek medical help in Australia ${ }^{20}$ and thus the potential direct medical costs may be higher if adequate services were available.

In addition to the direct health system costs, mental illness also has significant additional costs to society, which are incurred indirectly through lost labour force participation for example. This study has quantified the indirect costs of mental illness through early retirement and the effect this has on individuals' wealth. However, there are additional costs because of early retirement. In previous studies it has been found that those retiring early as a result of depression pay $96 \%$ less tax (tax on income from all sources), and those with other mental illnesses pay $91 \%$ less tax than those who are healthy and remain in the labour force (details available from the author on request). Further, in 2006, 101936 people with psychological/psychiatric disorders who were over the age of 45 claimed a Disability Support Pension, adding to the cost of mental illness to the state. ${ }^{21}$ (The Disability Support Pension is AU\$644.20 ( $£ 354.31$ ) per week for single people and AU\$485.60 ( $£ 267.08$ ) each for couples. In total, AU\$1468 million in Disability Support Pension payments are made to Australians aged 45-54 years of age per annum).

Analyses of the numbers needed to treat (NNT) to achieve good clinical outcomes for people with depression have demonstrated high efficacy: most antidepressants an NNT $<5 .{ }^{22}$ Given the low cost and cost-effectiveness of these drugs ${ }^{23-25}$ the cost to the government of appropriate treatment is likely to be more than offset by reductions in the Disability Support Pension payments.

The Australian universal healthcare system and more generous social security system may to some extent help to protect

\begin{tabular}{|c|c|c|c|c|c|}
\hline Wealth class & Population with this asset type & $n$ & $\%$ & OR $(95 \% \mathrm{Cl})$ & $P$ \\
\hline \multicolumn{6}{|l|}{ Cash } \\
\hline Employed full time, no condition & 1102671 & 1732 & 78.4 & 1 & \\
\hline Employed part time, no condition & 330764 & 638 & 79.1 & $1.07(0.78-1.46)$ & 0.695 \\
\hline Not in labour force owing to depression & 18114 & 31 & 71.8 & $0.72(0.29-1.76)$ & 0.4664 \\
\hline Not in labour force owing to other mental illness & 31956 & 45 & 81.6 & $1.23(0.51-2.98)$ & 0.6482 \\
\hline \multicolumn{6}{|l|}{ Superannuation } \\
\hline Employed full time, no condition & 1312882 & 2105 & 93.3 & 1 & \\
\hline Employed part time, no condition & 358589 & 674 & 85.8 & $0.40(0.27-0.59)$ & $<0.0001$ \\
\hline Not in labour force owing to depression & 7866 & 13 & 31.2 & $0.03(0.02-0.08)$ & $<0.0001$ \\
\hline Not in labour force owing to other mental illness & 8811 & 18 & 22.5 & $0.02(0.01-0.05)$ & $<0.0001$ \\
\hline \multicolumn{6}{|l|}{ Home equity } \\
\hline Employed full time no condition & 1252878 & 1971 & 89.0 & 1 & \\
\hline Employed part time no condition & 389209 & 709 & 93.1 & $1.57(0.99-2.50)$ & 0.0557 \\
\hline Not in labour force owing to depression & 18939 & 27 & 75.1 & $0.35(0.16-0.75)$ & $<0.05$ \\
\hline Not in labour force owing to other mental illness & 21864 & 32 & 55.8 & $0.16(0.07-0.36)$ & $<0.0001$ \\
\hline \multicolumn{6}{|l|}{ Other financial investments } \\
\hline Employed full time, no condition & 719575 & 1142 & 51.1 & 1 & \\
\hline Employed part time, no condition & 213800 & 391 & 51.2 & $1.05(0.81-1.35)$ & 0.7174 \\
\hline Not in labour force owing to depression & 8288 & 11 & 32.8 & $0.50(0.20-1.27)$ & 0.1434 \\
\hline Not in labour force owing to other mental illness & 9338 & 13 & 23.9 & $0.33(0.15-0.76)$ & $<0.05$ \\
\hline
\end{tabular}


Table 4 Sensitivity analysis - value of, and odds ratio of having, all wealth assets for those with depression and other mental illness who are out of the labour force for any reason and those who are in full-time and part-time employment with no condition, for people with any wealth

\begin{tabular}{|c|c|c|c|c|c|c|c|c|}
\hline \multirow[b]{2}{*}{ Total wealth } & \multicolumn{5}{|c|}{ Those with any wealth } & \multicolumn{3}{|c|}{ Value of wealth ${ }^{\mathrm{e}}$} \\
\hline & $\begin{array}{c}\text { Population } \\
\text { with any } \\
\text { wealth }^{\mathrm{a}}\end{array}$ & $n^{\mathrm{b}}$ & $\%^{c}$ & $\begin{array}{l}\text { OR }(95 \% \mathrm{Cl}) \\
\text { of having } \\
\text { wealth }^{\mathrm{d}}\end{array}$ & $P$ & $\begin{array}{l}\text { Mean value } \\
\text { of wealth, } \\
\text { AU\$ (f) }\end{array}$ & s.d. & $\begin{array}{c}\text { Median value } \\
\text { of wealth, } \\
\text { AU\$ (f) }\end{array}$ \\
\hline Employed full time, no condition & 1403163 & 2256 & 99.7 & 1 & & $\begin{array}{c}398098 \\
(218954)\end{array}$ & 490038 & $\begin{array}{c}255199 \\
(140359)\end{array}$ \\
\hline Employed part time, no condition & 417098 & 774 & 99.8 & $2.37(0.51-10.96)$ & 0.2700 & $\begin{array}{c}360071 \\
(198039)\end{array}$ & 405432 & $\begin{array}{c}225652 \\
(124109)\end{array}$ \\
\hline Not in labour force owing to depression & 41124 & 74 & 86.8 & $0.03(0.01-0.12)$ & $<0.0001$ & $\begin{array}{l}273824 \\
(150603) \\
\end{array}$ & 452572 & $\begin{array}{c}212695 \\
(116982)\end{array}$ \\
\hline Not in labour force owing to other mental illness & 78359 & 115 & 89.7 & $0.03(0.01-0.08)$ & $<0.0001$ & $\begin{array}{c}206886 \\
(113787)\end{array}$ & 315729 & $\begin{array}{l}112315 \\
(61773)\end{array}$ \\
\hline \multicolumn{9}{|c|}{$\begin{array}{l}\text { a. All Australians aged } 45 \text { to } 64 \text { who have any wealth. } \\
\text { b. The number of records in Health \& WealthMOD of those aged } 45-64 \text { who have any wealth. } \\
\text { c. The proportion of individuals in the } 45 \text { - to } 64 \text {-year-old population who have any wealth. } \\
\text { d. Adjusted for age, gender and education. } \\
\text { e. In } 2009 \text { Australia dollars (AUS): } 1 \text { AU } \$=\text { approximately f0.55. }\end{array}$} \\
\hline
\end{tabular}

\begin{tabular}{|c|c|c|c|}
\hline Labour force status & $\%$ increase & $P$ & $95 \% \mathrm{Cl}$ \\
\hline Employed full time, no condition & 0 & & \\
\hline Employed part time, no condition & -6.51 & 0.4683 & -22.07 to 12.15 \\
\hline Not in labour force owing to depression & -77.80 & $0.0047^{a}$ & -92.17 to -37.09 \\
\hline Not in labour force owing to other mental illness & -93.21 & $0.0003^{a}$ & -98.44 to -70.45 \\
\hline a. Significant at the 0.05 level. & & & \\
\hline
\end{tabular}

individuals with depression and other mental illness from loss of all their savings and associated deterioration in living standards. Nonetheless, the savings of those with depression and other mental illness are still significantly compromised relative to those who are well. This study showed that if people out of the labour force because of depression or other mental illness do have any wealth, on average they have AU\$236727 ( $\$ 130200)$ and AU\$148771 ( $£ 81824)$ in accumulated wealth respectively. This is far lower than the amount held by those in full- and part-time employment without ill health.

This lower amount of accumulated wealth is likely to result in lower living standards for these individuals. Wealth is generally used to protect against unexpected events (such as a deterioration in health), finance large financial commitments (such as children's education), and also allow for general daily consumption. ${ }^{26-28}$ Indeed Dvornak \& Kohler found that a $\$ 1$ increase in the value of wealth stored in housing assets is likely to result in a $3 \%$ increase in consumption spending. ${ }^{28}$

\section{Findings from other studies}

The quantification of lost savings and wealth because of mental illness has not been reported in other studies. Furthermore, there have been few studies on the impact of ill health in general on savings or wealth with which to compare these findings. However, one study conducted in the USA by Covinsky et al found that 38\% of patients aged 45-64 lost all or most of their savings owing to illness. ${ }^{29}$ More recently, another USA study by Swoboda \& Lipsett found similar results, with $36.7 \%$ of families losing most of their savings as the result of having a family member critically ill for 12 months or more. ${ }^{30}$ However, these studies only considered the impact on savings, and did not consider other wealth assets available to individuals such as home equity or investment properties, nor did they quantify the value of wealth held by individuals, as our study did.

\section{Implications}

Although comorbidities may contribute to the reduced labour force participation, and hence income and wealth accumulation, of people with mental illness, the analysis undertaken focused on people who identified their mental illness as their main health condition, and their health condition as being the reason for retirement. Other people who identified other illnesses as their main condition may have a concurrent mental illness that also contributes to their non-participation in the labour force. Thus, it is likely that our analysis has underestimated the total impact of mental illness on individuals' wealth accumulation.

The Council of Australian Government has developed a National Action Plan on Mental Health 2006-2011, which is based upon a commitment to the prevention of mental illness and early intervention (depression was included under the broader term of 'mental illness' in the plan). ${ }^{31}$ Prevention and early intervention is anticipated to reduce the severity, length and reoccurrence of mental illness, and will focus on increasing access to health services. ${ }^{31}$ New Horizons: A Shared Vision for Mental Health, published by the UK Department of Health, explores the need for prevention and early treatment of mental illness. ${ }^{32}$ It recognises that doing this will have economic benefits because of the large financial burden of mental illness on the state.

Preventing mental illness is likely to be a cost-effective activity for governments, and in the long term save on the costs of financially supporting those who are forced to exit the workforce early because of their ailment and thus are unable to support 
themselves financially. This paper has shown that those who have retired early as a result of mental ill health will not only have a loss of immediate income from employment but also have very low value of wealth assets and savings - thereby drastically reducing their ability for financial self-sufficiency. Thus the responsibility of providing financial support for these individuals falls to the state - a hefty financial burden that may be avoided through actions to prevent the occurrence of mental illness.

The ultimate aim of the Australian National Action Plan on Mental Health 2006-2011 is to allow individuals to live 'independent and fulfilling lives', which includes increasing capacity for labour force participation. ${ }^{31}$ Although this study looked at the impact of depression and other mental illness separately, and showed that each condition has different effects on wealth accumulation, the findings of our study highlight the need for such overall preventive action, in light of the costs to both individuals and to governments as the result of early retirement because of ill health.

Deborah J. Schofield, PhD, Rupendra N. Shrestha, PhD, NHMRC Clinical Trials Centre and School of Public Health, University of Sydney; Richard Percival, BA (Hons), Simon J. Kelly, PhD, NATSEM, University of Canberra; Megan E. Passey, BMed (Hons), MPH, MSc, Northern Rivers University Department of Rural Health,

school of Public Health, University of Sydney, Australia; Emily J. Callander, BA(Env), NHMRC Clinical Trials Centre, University of Sydney, Australia

Correspondence: Deborah J. Schofield, NHMRC Clinical Trials Centre, 92-94 Parramatta Road, Camperdown NSW 1450, Australia. Email: deborah.schofield@ctc.usyd.edu.au

First received 21 Apr 2010, final revision 12 Aug 2010, accepted 28 Sep 2010

\section{References}

1 Boston Consulting Group. Improving Mental Health Outcomes in Victoria: The Next Wave of Reform. Boston Consulting Group, 2006.

2 Patel A, Knapp M. Costs of mental illness in England. Men Health Res Rev 1998; 5: 4-10.

3 Department of Health and Ageing. National Mental Health Report 2007: Summary of Twelve Years of Reform in Australia's Mental Health Services under the National Mental Health Strategy, 1993-2005. Commonwealth of Australia, 2007.

4 Waghorn G, Lloyd C. The Employment of People with a Mental Illness: A Discussion Document Prepared for the Mental Illness Fellowship of Australia. University of Queensland, 2005.

5 Schofield DJ, Shrestha RN, Passey ME, Earnest A, Fletcher SL. Chronic disease and labour force participation among older Australians. Med J Aust 2008; 189: 447 .

6 Miles D. Modelling the impact of demographic change upon the economy. Econ J 1999: 109: 1-36.

7 Bloom DE, Canning D. The health and wealth of nations. Science 2000; 287 1207-9.

8 Sala-i-Martín X. On the health poverty trap. In Health and Economic Growth Findings and Policy Implications (eds G Lopez-Casasnovas \& L Currais). The MIT Press, 2005

9 Zhang J, Zhang J. The effect of life expectancy on fertility, saving, schooling and economic growth: theory and evidence. Scand J Econ 2005; 107: 45-66.
10 Brazenor R. Disabilities and labour market earnings in Australia Aust J Labour Econ 2002; 5: 319-34.

11 Rosen HS, Wu S. Portfolio choice and health status. J Financ Econ 2004 72: $457-84$.

12 Wenzlow AT, Mullahy J, Robert SA, Wolfe BL. An Empirical Investigation of the Relationship between Health and Wealth using the Survey of Consumer Preferences. Institute for Research on Poverty, University of Wisconsin-Madison, 2004.

13 Australian Bureau of Statistics. Information Paper - Basic Confidentialised Unit Record File: Survey of Disability, Ageing and Carers 2003 (reissue). Australian Bureau of Statistics, 2005.

14 Lambert S, Percival R, Schofield D, Paul S. An Introduction to STINMOD: A Static Microsimulation Model. Report No.: STINMOD Technical Paper No. 1. NATSEM, 1994

15 World Health Organization. The ICD-10 Classification of Mental and Behavioural Disorders: Clinical Descriptions and Diagnostic Guidelines. WHO, 1992.

16 Organisation for Economic Co-operation and Development. Purchasing Power Parities: Consumer Price Levels. OECD, 2010.

17 Vos T, Haby M, Barendregt J, Kruijshaar M, Corry J, Andrews G. The burden of major depression avoidable by longer-term treatment strategies. Arch Gen Psychiatry 2004; 61: 1097.

18 Begg S, Vos T, Barker B, Stevenson C, Stanley L, Lopez AD. The Burden of Disease and Injury in Australia 2003. Australian Institute of Health and Welfare, 2007

19 Australian Institute of Health and Welfare. Health System Expenditure on Disease and Injury in Australia 2000-01. AlHW, 2004.

20 Andrews G, Hall W, Teesson M, Henderson S. The Mental Health of Australians. Commonwealth Department of Health and Aged Care, 1999.

21 Centrelink Performance and Information Branch. Data Request BI3268: Health Conditions associated with Sickness Benefits and Disability Support Pension, 13 Jan 2006. Centrelink Performance and Information Branch, 2006.

22 Katona C, Livingston G. How well do antidepressants work in older people? A systematic review of number needed to treat. J Affect Disord 2002; 69: 47-52.

23 Barretta B, Byforda S, Knappa M. Evidence of cost-effective treatments for depression: a systematic review. J Affect Disord 2005; 84: 1-13.

24 Jonsson B, Bebbington PE. What price depression? The cost of depression and the cost-effectiveness of pharmacological treatment. Br J Psychiatry 1994; 164: 665-73.

25 Doyle JJ, Casciano J, Arikian S, Tarride J, Gonzalez MA, Casciano R. A multinational pharmacoeconomic evaluation of acute major depressive disorder (MDD): a comparison of cost-effectiveness between venlafaxine, SSRIS and TCAs. Value Health 2001; 4: 16-31.

26 Cagetti M. Wealth accumulation over the life cycle and precautionary savings. J Bus Econ Statist 2003; 21: 339-53.

27 Caner A, Wolff EN. Asset poverty in the United States 1984-99: evidence from the panel study of income dynamics. Rev Income Wealth 2004; 50: 493-518.

28 Dvornak N, Kohler M. Housing wealth, stockmarket wealth and consumption: a panel analysis for Australia. Econ Rec 2007; 83: 117-30.

29 Covinsky KE, Goldman L, Cook EF, Oye R, Desbiens N, Reding D, et al. The impact of serious illness on patients' families. JAMA 1994; 272: 1839-44.

30 Swoboda SM, Lipsett PA. Impact of a prolonged surgical critical illness on patients' families. Am J Critical Care 2002; 11: 459-66.

31 Council of Australian Governments. National Action Plan on Mental Health 2006-2011. COAG, 2006.

32 Mental Health Division Department of Health. New Horizons: A Shared Vision for Mental Health. UK Department of Health, 2009. 